\title{
Potential for the Use of Exogenous Chemical Elicitors in Disease and Insect Pest Management of Conifer Seedling Production
}

\author{
J.K. Holopainen ${ }^{*}, 1$, J. Heijari ${ }^{1}$, A.-M. Nerg ${ }^{1}$, M. Vuorinen ${ }^{2}$ and P. Kainulainen ${ }^{1}$ \\ ${ }^{1}$ Department of Environmental Science, University of Kuopio, P.O. Box 1627, FI-70211 Kuopio, Finland \\ ${ }^{2}$ The Finnish Forest Research Institute, Suonenjoki Research Station, FI-77600 Suonenjoki, Finland
}

\begin{abstract}
Elicitors are compounds, which activate chemical defences in plants. Various biosynthetic pathways are activated in treated plants depending on the compound used. The most intensively studied elicitor for manipulating defence pathways in plants is methyl jasmonate, which modifies e.g. the production of terpenoids, the main constituents of conifer oleoresin. Other commonly tested chemical elicitors are salicylic acid, methyl salicylate and benzothiadiazole, which affect production of phenolic compounds in plants. Both jasmonate-based and salicylate-based elicitors have been shown to have suppressive effects on fungal diseases and insect pests of plants. So far, knowledge regarding the efficiency of elicitor treatments for enhancing pest and fungal disease resistance of conifer seedlings is very limited. We review current knowledge of the effect of these elicitor compounds on pest and disease resistance in plants, and we analyze the potential pros and cons of using elicitors for future pest management strategies in forest nurseries.
\end{abstract}

Keywords: Induced defence, indirect defence, plant volatiles, terpenoids, priming, MeJA, MeSA, BTH.

\section{INTRODUCTION}

Boreal conifer forests form the largest biome on Earth. When growing actively these forests are considered to be one of the most significant global sinks of atmospheric $\mathrm{CO}_{2}[1]$. Regeneration of conifer forests with good quality seedling material is essential for maintaining the large forested areas as an active $\mathrm{CO}_{2}$ sink after forest logging. Along with global warming the pressure by pest insects and mites and various plant pathogens will be an increasing threat to forestry in boreal forest areas in the future [2].

Feeding injuries caused by insects and mites, or attack by fungal hyphae and pathogenic bacteria, will elicit natural defence mechanisms in plants [3]. Chemical defences against herbivorous organisms can be direct, affecting feeding or reproduction of an herbivore, or indirect, suppressing the impact of harming organisms by attracting or maintaining the natural enemies of herbivores [3,4]. This will include activation of genes involved in certain biochemical pathways in plants to produce enzymes, which are responsible for production of secondary metabolites. These secondary plant metabolites are active chemical compounds that are not normally essential for basic plant physiology, but have e.g. a defensive role against herbivores and pathogens. In conifers, terpene-based chemical defence is dominant, while in the whole plant kingdom terpenoids are the most diverse group of plant secondary metabolites with over 40,000 known compounds, when all derivates of the universal precursors isopentenyl diphosphate (IPP) and its isomer, dimethylallyl diphosphate (DMAPP) are considered [5]. Major terpenoids in oleoresin are the ten-carbon monoterpenes, 15-carbon

*Address correspondence to this author at the Department of Environmental Science, University of Kuopio, P.O. Box 1627, FI-70211 Kuopio, Finland; E-mail: jarmo.holopainen@uku.fi sesquiterpenes and 20-carbon diterpenes [6]. Production of genetically modified conifer trees with increased resin-based defence capability has been proposed earlier [7]. Recently, conifers treated with exogenous elicitors e.g. methyl jasmonate (MeJA) have shown increased resin production and resistance against herbivores [8]. The terpene-derived alcohol paclitaxel (taxol) is also used as a pharmaceutical agent against cancer. Production of this compound in Taxus sp. cell cultures can be efficiently up-regulated by specific external stimuli such as MeJA elicitor [9]. Thus, elicitor compounds affect the synthesis of chemical compounds in plants, but this will result in constraints in carbon allocation and ultimately reduce plant growth or even stop the shoot elongation after the elicitor treatment [8]. Therefore, detailed investigations of the whole plant physiological and growth responses after manipulation of induced defences are needed.

\section{MECHANISM OF INDUCED DEFENCES IN PLANTS}

Plant defence, including physical defence based on e.g. cuticle structure, various thorns and hairs, and chemical defence based on chemical compounds can be divided into constitutive and inducible defence component [3]. Constitutive defence can be found in healthy plants that are not harmed by biotic or abiotic stressors. In many circumstances, constitutive defence is not enough to protect against attack by microbes or herbivores. When an insect takes a bite, or the appressorium of fungal hyphae attacks the plant cells causing lysis and disintegration of cell membranes, the defence responses of the plant are activated. Biological or abiotic induction will lead to formation of new protective plant structures or production of new chemical compounds in plant tissues and if volatile, they may be emitted. After fungal pathogen and insect herbivore attack there is also an increase in chemical compounds that are already found constitutively in healthy plants. Tissue concentrations and volatile emissions of organic compounds may both be elevated, but re- 
sponsiveness of different compounds depends on the type of attacking organism e.g. [10].

\section{INDUCIBLE BIOSYNTHETIC PATHWAYS IN PLANTS}

In this section, the three major biochemical pathways, leading to the formation of plant secondary metabolites, i.e. terpenoids, phenolics and alkaloids, will be briefly described. Many plant families have specific pathways producing compounds, which are very responsive to elicitors like glucosinolates in crucifers [11], but these compounds are not found in conifers.

Plant terpenoids are formed via two separate pathways, which are active in different sub-cellular compartments. The methylerythritol phosphate pathway (MEP) is active in plastids including chloroplasts. MEP pathway is mostly responsible for the production of isoprene and monoterpenes, but recent observations by Phillips et al. [7] have suggested that the MEP pathway is primarily responsible for providing precursors for induced oleoresin biosynthesis and their major compounds, diterpenes.

Acetate-mevalonate pathway (MVA) is active in the cytosol where sesquiterpenes are produced [12]. Both pathways produce isopentenyl diphosphate (IPP), which is transformed to form terpene precursors. Some plant stress-related inducible terpenes like the homoterpene 4,8-dimethyl-1,3,7nonatriene (DMNT) are produced via both of the two terpene pathways [12] giving evidence of cross-talk between the pathways. This is an indication that there is a dynamic pathway allocation, when plants are under stress and terpenes are urgently needed for plant defence.

Plant phenolics are synthesized by several different biosynthetic pathways, but mainly via the shikimic acid and malonic acid pathways. Plant phenolics are a very diverse group of plant secondary compounds from six carbon simple phenolics to polymeric tannins, which have monomer units of phenolics [13].

Plant alkaloids are a large group of nitrogen-containing plant secondary compounds formed from common amino acids, lysine, tyrosine, tryptophan and ornithine. Alkaloids are toxic to many herbivores and have medicinal properties [14]. Keinänen et al. [15] have demonstrated that alkaloids respond to exogenous elicitors among the other major groups of plant chemicals.

\section{EXOGENOUS ELICITORS}

Elicitors tested for pest management purposes are usually synthetically produced molecules of the chemical compounds, which normally have an endogenous hormone role in controlling plant defence. Furthermore, fungal cell wall components like alamethicin peptide [16] and chemical compounds in insect saliva or regurgitant can act as natural elicitors (Fig. 1).

Ethylene, $\mathrm{C}_{2} \mathrm{H}_{4}$ is a natural plant hormone. An ethylenereleasing substance 2-chloroethylphosphonic acid (Ethephon) activates stilbene production and increases the number of pathogenesis-related proteins in grapevine leading to the protection against fungal pathogens [17].

Methyl jasmonate (MeJA), (Z,E)-methyl 3-oxo-2-(2pentyl) cyclopentane acetate is a plant hormone formed via the octadecanoid pathway together with jasmonic acid (JA) [18]. JA and MeJA are formed in plants under various biotic stresses. Biosynthesis is believed to start with the oxygenation of free linolenic acid (LA), with further reactions catalysed by a lipoxygenase (LOX) enzyme. MeJA is a catabolite of JA and both activate genes controlling the secondary metabolic pathways. Synthetic octa-decanoid phytohormone mimic compounds like coronalon (6-ethyl indanoyl isoleucine conjugate) are highly active elicitor compounds inducing similar responses in several plant species [18].

Methyl salicylate (MeSA), methyl-2-hydroxybenzoate is an organic ester and natural product of many plant species. MeSA can be produced by esterifying salicylic acid (SA), which as a natural plant hormone, affects e.g. plant growth and development and acts as a signal in plant defence. The compound was registered as a pesticide for the first time in 1972, when it was classified as an insect repellent [19].

BTH, benzo-(1,2,3)-thiadiazole-7-carbothioic acid Smethyl ester is a functional analogue of salicylic acid and marketed with the trade names Bion and Actigard. It has been shown to induce resistance to a wide variety of plant pathogens and to have efficiency comparable to that of traditional fungicides in controlling e.g. Peronospora species [20].

Chitosan is a non-toxic and biodegradable polymer of beta-1,4-glucosamine. It is a deacetylated form of chitin derived from crustaceous shells such as those of crabs and shrimps. Chitosan has a direct effect on treated microorganisms reflecting its fungicidal potential, but it also induces a series of defence reactions in treated plants [21].

\section{ELICITOR IMPACTS ON CONIFER XYLEM CEL- LULAR STRUCTURE AND CHEMISTRY}

MeJA is one of the most commonly studied elicitors on coniferous trees. MeJA treatment affects the synthesis of terpenoids. Therefore, it influences the cellular structures where synthesis and storage of conifer oleoresin takes place [22], [23]. Hudgins et al., [24] found that in several Pinaceae species MeJA induced a response partly similar to wounding, including polyphenolic parenchyma (PP) cell activation and xylem traumatic resin duct (TD) formation. MeJA treatment induces xylem TD formation and surface resinosis in members of the Taxodiaceae family, formation of axial phloem resin ducts but not xylem ducts in the Araucariaceae and Cupressaceae families, whereas Podocarpaceae species showed no induction of resin-producing structures. In Scots pine (Pinus sylvestris) seedlings MeJA treatment induced the formation of resin ducts in a continuous band in newly developing stem xylem [8]. Resin duct density was significantly increased in xylem cross-sections of Scots pine seedlings (Fig. 2). Furthermore, MeJA treatment in concentration of $100 \mathrm{mM}$ reduced annual diameter growth and tracheid cell lumen area, but no effects were seen in thickness of bark and phloem [8]. In another MeJA experiment with saplings of four Scots pine provenances, only one provenance showed MeJA induced reduction in stem diameter [25]. All Pinaceae species treated with MeJA showed phenolic deposition in polyphenolic parenchyma cells, and early lignification of phloem fibres was observed in most of the studied nonPinaceae species [22]. 
<smiles>N[C@H]1C(O)[C@H](O[C@@H]2O[C@H](CO)[C@@H](O)C(O)[C@H]2N)[C@H](CO)O[C@H]1O</smiles>

Q Ho $\mathrm{S}_{\mathrm{O}}^{\mathrm{NH}_{2}}$ Chitosan<smiles>CSC(=O)c1cccc2nnsc12</smiles>

BTH<smiles>COC(=O)c1ccccc1O</smiles><smiles>CCc1cc2c(c(C(=O)N[C@H](C(=O)OC)[C@H](C)CC)c1)CCC2=O</smiles>

Coronalon<smiles>CC/C=C\CC1C(=O)CCC1CC(=O)OC</smiles><smiles>O=P(O)(O)CCCl</smiles>

Ethephon<smiles>C=C</smiles>

Ethylene

Methyl salicylate Methyl jasmonate

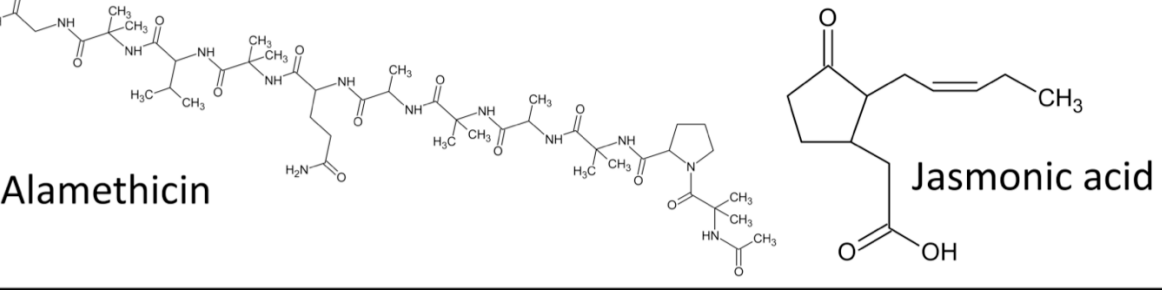

Fig. (1). Structures of the elicitor compounds.

Application of $0.01 \%$ MeJA to the soil of potted Douglas-fir seedlings (Pseudotsuga menziesii (Mirb.) Franco) caused numerous anatomical and chemical changes in the roots, stem and foliage. These changes were, for the most part, similar for both studied full-sibling families. One of the most distinctive changes was induced traumatic resin duct formation in roots and stems [26]. Similar formation of traumatic resin ducts was reported by Alfaro et al. [27] to occur in the developing xylem of trees following insect attack. Development of traumatic resin ducts is expected to allow trees to move induced resin to the site of damage as a rapid and targeted defence against herbivores or invading pathogens. Chemical differences between MeJA-treated and control Douglas-fir seedlings were mainly limited to the roots and stem, though some changes also occurred in the foliage [26]. In stems some diterpenes were increased 25fold in concentration, which was probably possible because of increased numbers of traumatic resin ducts.

\section{IMPACTS OF ELICITORS ON PLANT DEFENCE CHEMISTRY}

The elicitors are compounds that have a natural function in plant signalling. Gene expression analysis by Phillips et al. [28] of Norway spruce (P. abies) demonstrated that genes encoding 1-deoxy-D-xylulose 5-phosphate synthase (DXS), which catalyzes the first step of the MEP pathway, are distinctly induced by the various elicitors. In cell cultures, the gene PaDXS2A was induced by treatment with chitosan, methyl salicylate, and Ceratocystis polonica (a bark beetleassociated, blue-staining fungal pathogen). However, another
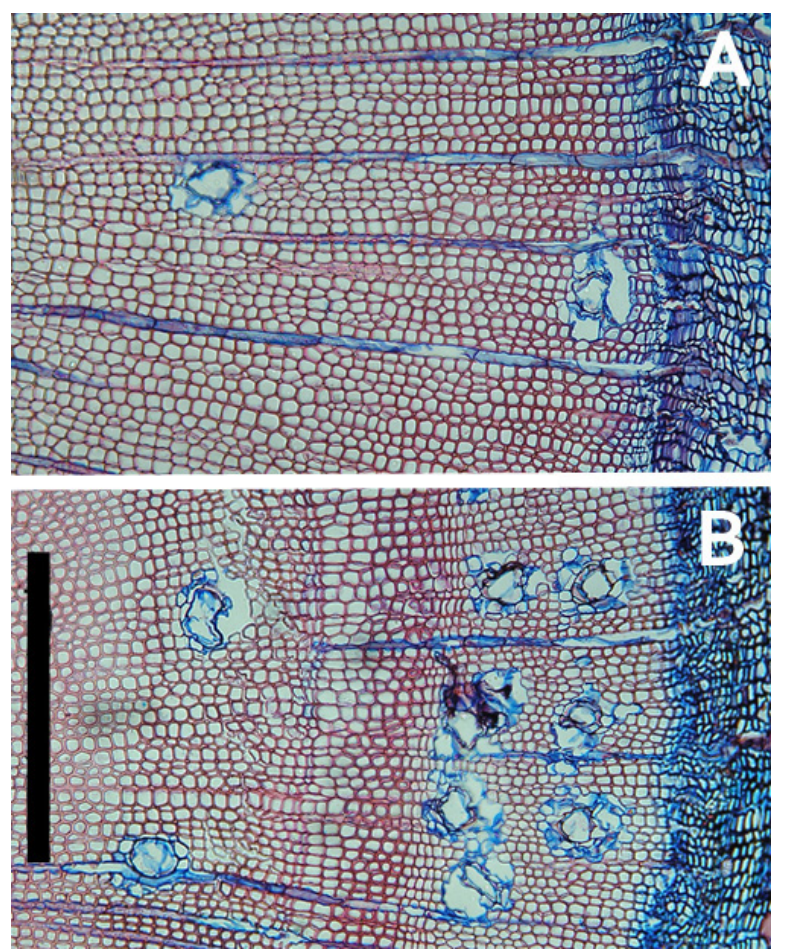

Fig. (2). Xylem cross-sections from stems of Scots pine (Pinus sylvestris) seedlings treated with (A) $0 \mathrm{mM}$ (control) or (B) with $100 \mathrm{mM}$ MeJA, showing MeJA effect on resin duct density (2 resin ducts in control and 9 in MeJA treatment). Red area is xylem and blue area on the right is cambium and phloem. Sections were stained with a mixture of safranin and alcian blue. Bar $=0.5 \mathrm{~mm}$. 
gene PaDXS2B was induced by treatment with MeJA and chitosan, but was not affected by MeSA or C. polonica. Monoterpene synthase was activated after application of MeJA to the growth medium and several monoterpenes accumulated in Norway spruce cell suspension culture. Chitosan and MeJA both activated genes encoding the pathogenesis-related 14-3-3 protein in seedlings and cell suspension cultures of White spruce Picea glauca [29].

Heijari et al. [8] observed that in Scots pine seedlings the total monoterpene concentration in the current-year xylem was significantly increased by $100 \mathrm{mM}$ MeJA treatment. Of the individual monoterpenes only the concentration of $\alpha$ pinene increased significantly. No changes in the total monoterpene concentration were observed in the current and previous-year bark or needles. The total resin acid concentration in the current-year needles and stem xylem was significantly higher in the $100 \mathrm{mM}$ treated than control seedlings. In needles of MeJA treated seedlings the concentrations of most individual resin acid compounds increased, whereas in stem xylem, only the concentration of abiotic acid increased. This was an indication of differential responses by various plant parts of conifer seedlings to spraying seedling foliage with MeJA. Another long-term MeJA treatment experiment [25] with Scots pine saplings demonstrated that foliar MeJA application affects needle secondary chemistry with significantly elevated concentrations of two monoterpenes, $\beta$ pinene and limonene. In two of the studied pine provenances MeJA increased the concentrations of resin acids in the needle oleoresin as well.

Soil treatment of Douglas fir seedlings with MeJA significantly increased the concentrations of most monoterpenes in roots and stems, whereas $(E)$ - $\beta$-ocimene decreased significantly in the foliage. Four of the five detected sesquiterpenes increased significantly, mainly in the root and stem, and four of the eight detected diterpenes increased in response to MeJA treatment, but only in root and stem tissues [26]. Miller et al. [30] compared the effects of attack by white pine weevils (Pissodes strobi) or application of MeJA -induced terpenoid responses in Sitka spruce (Picea sitchensis). Both insects and MeJA caused traumatic resin accumulation in stems, with more accumulation induced by the weevils.

\section{ELICITOR IMPACTS ON PLANT PATHOGENS ON CONIFERS}

Krokene et al. [31] investigated the effect of chemical pre-treatment with MeJA or oxalic acid (OxA) on pathogen resistance of 13-year-old Norway spruce trees. The outer bark of test trees was first treated with chemical and then 4 weeks later inoculated with the pathogenic blue-stain fungus Ceratocystis polonica. Both chemicals significantly reduced symptoms of fungal infection, but MeJA was more effective than OxA (51 versus $18 \%$ reduction in length of necrotic lesions in the phloem relative to untreated control trees). The authors concluded that MeJA treatment of Norway spruce appears to have practical potential as a tool for increasing plant resistance to fungal infection, but with a modest reduction in sapwood growth. Kozlowski et al. [32] found that fumigation of $P$. abies seedlings with MeJA ( 3 days, $25 \mu 1$ $1001^{-1}$ air) protected seedlings from Pythium ultimum infection by up to $75 \%$. There was not a direct fungitoxic effect of MeJA, but the accumulation of free salicylic acid (SA) in all parts of the seedlings was found, whereas bound SA increased only in hypocotyls and cotyledons.

The only report of BTH effects on pathogen resistance in conifers indicated that foliar sprays of BTH, separately and in combination with potassium phosphonate, reduced incidence of Phytophthora root rot on Pinus radiata and on other cultivated plants [33].

\section{ELICITOR IMPACTS ON PEST ARTHROPODS}

Insects and mites, both arthropods, are the most important invertebrate herbivores, which damage conifer seedlings. Heijari et al. [8] tested the feeding behaviour of the large pine weevil (Hylobus abietis L., Coleoptera: Curculionidae) on the MeJA-treated seedlings of Scots pine. The adult weevils gnawed a significantly smaller area of stem bark in the $100 \mathrm{mM}$ MeJA-treated plants than in the control or $10 \mathrm{mM} \mathrm{MeJA-treated} \mathrm{plants.} \mathrm{Interestingly,} \mathrm{the} 100 \mathrm{mM}$ MeJA-treatment increased the resin acid concentration in the needles and xylem, but not in the bark. Both MeJA treatments increased the number of resin ducts in newly developing xylem. However, the resin acid concentration increased in the bark and decreased in the xylem of the H. abietis gnawed seedlings compared to non-gnawed seedlings. This observation suggests that the resin might have flowed from surrounding tissues to the bark, and that this possibly created a chemical and physical barrier to the insects. It is also possible that bark tissues might have simultaneously undergone de novo synthesis of resin terpenoids [34] as a response to feeding damage.

Foliar MeJA application to Scots pine saplings representing four seed origins in three successive years affected needle secondary chemistry and significantly increased concentrations of some monoterpenes [25]. The growth rates of pine sawfly larvae of the species Neodiprion sertifer and Diprion pini were reduced on needles of MeJA-treated plants with either high total terpene or resin acid concentration [25].

\section{CROSS PROTECTION WITH ELICITOR TREAT- MENTS}

So far there are no reports on conifers where impacts of elicitor treatment on herbivores concurrent with other herbivores or pathogens were studied. Omer et al. [35] investigated on grapevines the effects of exogenous applications of the natural plant inducer, jasmonic acid (JA) on induced resistance to the folivorous Pacific spider mite, Tetranychus pacificus, as well as the root-feeding grape phylloxera, Daktulosphaira vitifoliae. Foliar jasmonic acid application at concentrations that caused no phytotoxicity significantly reduced the production of eggs by both herbivores when they were feeding on treated plants [35]. Negative cross-talk between the jasmonate and salicylate response pathways has been observed on tomato. The bacterial pathogen, Pseudomonas syringae showed reduced lesion development on tomato plants treated with BTH and showing activated salicylate responses, while resistance to $P$. syringae was not reduced or enhanced in dual-elicited (BTH \& JA) plants [36]. In a wild tomato cultivar BTH did not influence performance of Spodoptera exigua caterpillars. In cultivated tomato, 


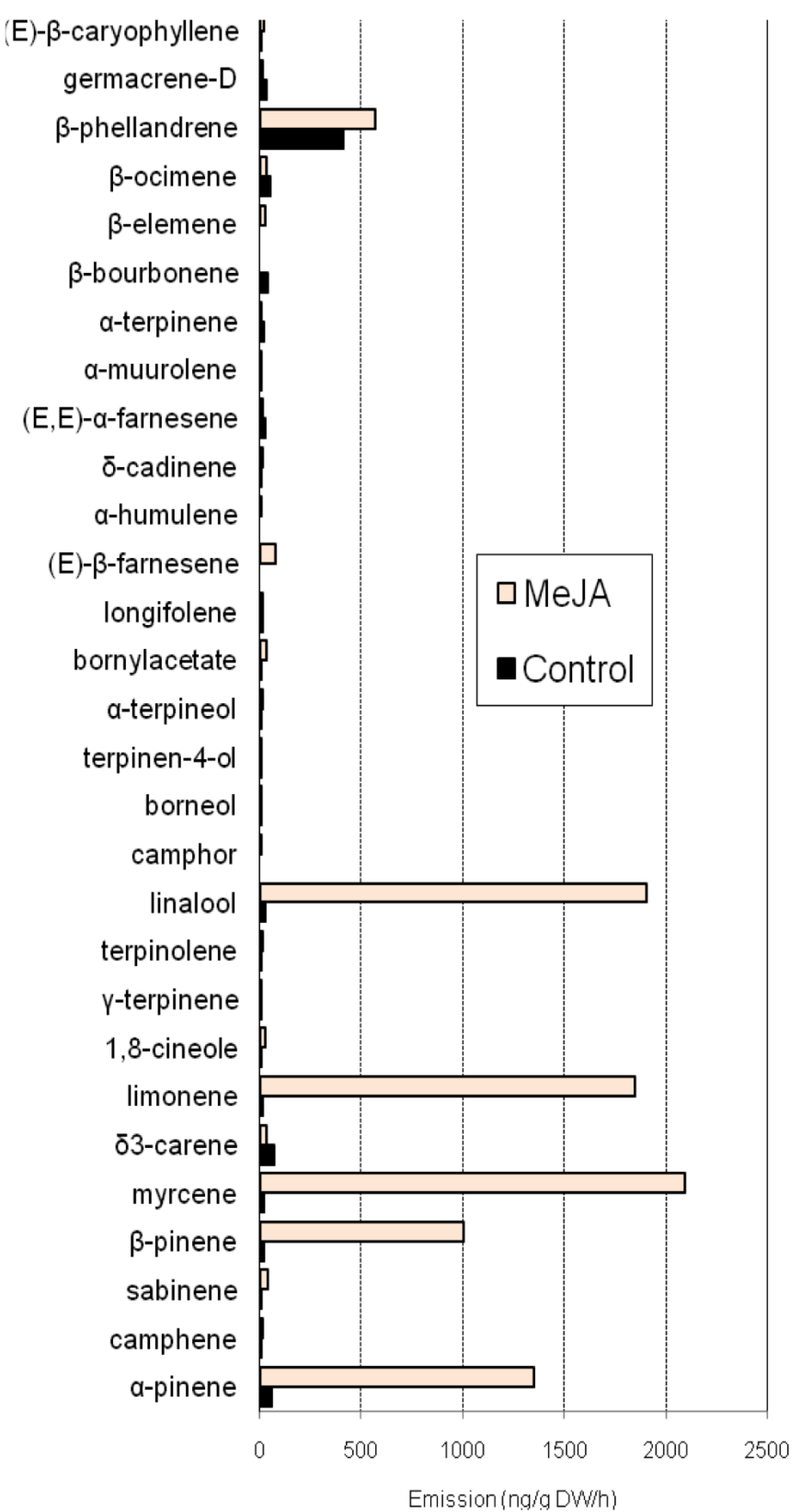

Fig. (3). Volatile organic compound (VOC) emission from twoyear-old Scots pine (Pinus sylvestris) seedlings sprayed with 30 $\mathrm{mM}$ MeJA or $0 \mathrm{mM}$ MeJA (control) $48 \mathrm{~h}$ before VOC sampling (Heijari et al. unpublished data).

reduced activity of a defense protein (polyphenol oxidase) in dual-elicited plants resulted in increased performance of $S$. exigua, but not thrips, spider mites, hornworm caterpillars or $P$. syringae bacteria [37]. The results indicate that the negative interactions between elicitors affecting jasmonate and salicylate signalling may have biological consequences on the efficiency against some insect pests. On the other hand, Boughton et al. [38] reported that a spraying with a mixture of BTH and MeJA on tomato has nearly as good efficiency against aphids as that of MeJA alone.

\section{ELICITOR IMPACTS ON PLANT VOC EMISSIONS AND NATURAL ENEMIES OF PESTS}

Inducible plant volatiles emitted after herbivore feeding have a significant role in the orientation behaviour of preda- tors and parasitoids of herbivores [39-41]. Jasmonic acid and MeJA treatment are known to induce similar emissions as herbivore feeding and therefore have some potential for making the treated plants attractive to natural enemies even before the herbivores arrive on cultivated plants [42]. Martin et al. [43] found that a $10 \mathrm{mM}$ MeJA spraying treatment triggered a 5-fold increase in total terpene emission from Picea abies foliage, with a shift in composition to a blend dominated by oxygenated monoterpenes (e.g. linalool) and sesquiterpenes (SQT) e.g. (E)- $\beta$-farnesene. $5.5 \mathrm{~h}$ after the treatment, no SQT emissions were detected, but after $32.5 \mathrm{~h}$ emissions contained five SQT and six induced monoterpene compounds. MeJA treatment also induced MeSa emissions. The rate of linalool emission increased more than 100 -fold and that of sesquiterpenes increased more than 30-fold. Kännaste et al. [44] found that the emissions from Norway spruce grafts, caused by Eriophyidae mite (Nalepella sp.) infestation had characteristic flower-like fragrances containing large amounts of sesquiterpenes $E$ - $\beta$-farnesene, $E, E-\alpha$ farnesene, monoterpene (-)-linalool, MeSA, and minute amounts of some other inducible terpenes and alcohols. These emission profiles, reported in two different studies, indicated that Norway spruce emissions after MeJA treatment have similar, but not identical profiles of inducible volatile compounds. Our own observations using a Scots pine (P. sylvestris) provenance (Fig. 3) indicated that MeJA treatment induces the volatile emissions of the monoterpenes linalool, limonene, myrcene, $\beta$-pinene and $\alpha$-pinene and sesquiterpenes $\mathrm{E}-\beta$-farnesene and $\beta$-phellandrene $48 \mathrm{~h}$ after treatment. Emissions of these compounds are also induced after feeding by pine weevils (H. abietis), but the quantity is lower and the ratios between the compounds are different (Heijari et al., unpublished).

Volatile terpenoid emission profile induced by white pine weevils (P. strobi) from Sitka spruce [30] was more complex than emission profile induced by MeJA treatment. Weevil feeding caused a rapid release of a blend of monoterpene olefins, presumably by passive evaporation of resin compounds from feeding damage sites in the bark stem. These rapidly released compounds were not found in MeJAinduced emissions. This study showed that the volatile organic compound (VOC) emissions induced by elicitors could be partly similar to certain herbivore-induced emissions, as there was a delayed emission of linalool from both treatments. Although the emission analysis indicated induced de novo biosynthesis of linalool the differences in emission profiles could be detected e.g. by natural parasitoids of weevils. Therefore MeJA treatment does not necessarily make seedlings as attractive to natural enemies of this herbivore as actual damage by the weevils.

There are no reports of the direct effects of elicitors on the behaviour of natural enemies of conifer pests. Ibrahim et al. [45] found that in Y-tube olfactometer tests with Cotesia vestalis the parasitoid of crucifer-feeding diamond back moth preferred odour of MeJA to filtered air. When released from traps MeJA and MeSA attracted parasitoids of the families Encyrtidae and Mymaridae to grapevines [46]. These observations indirectly suggest that MeJA treatment could have potential in attracting natural enemies of conifer seedling pests to intact plants if seedlings are treated before attack by pest insects and mites. However, the risk of in- 
creased preference of pest insect species for elicitor-treated plants is possible.

\section{PROS AND CONS OF ELICITOR TREATMENTS}

Phillips and Croteau [7] listed the possibilities of genetic engineering to manipulate oleoresin formation and conifer resistance against bark beetle attack. These included a) improvement of the speed and the level of response at the critical early stages of bark beetle attack, b) increasing the concentrations of natural compounds that are particularly toxic to invaders and c) introducing new defence genes. Elicitors currently provide an excellent tool for simulating the effects of genetic engineering for enhanced monoterpene and diterpene production in conifers. Elicitor-treated plants have higher concentrations of oleoresin, and concentrations of some compounds in the oleoresin are more distinctly increased after treatment than others. Furthermore, elicitortreated plants contain and emit some sesquiterpenes, which are not found in healthy untreated plants. Many of these elicitor-induced compounds are known to attract natural enemies of pests, indicating that elicitor treatment may allow the creation of a "buffer" of herbivore enemies before the expected attack by pest species.

The use of elicitors in crop protection and pest management is still in the very early stages of use as a new control method, and thus the current experiences come from experimental trials, and not yet from large scale agricultural use. In forest tree production the use of elicitors is even more limited. Therefore, the following summary of advantages and disadvantages of elicitor technique is based mostly on smallscale field trials or growth chamber and greenhouse experiments with conifer trees. In addition practical experience of elicitors in crop plant production is considered. At least the following advantages of using elicitor treatments have been reported or can be expected:

- $\quad$ insect feeding damage is reduced [8].

- $\quad$ reduced symptoms of fungal infection [31].

- $\quad$ reduced growth rate of herbivores on elicitor-treated plants [25] may increase the mortality of pests.

- $\quad$ promotion of natural biological control by inducing plant volatiles that attract natural enemies of pest insects [45], [46].

- $\quad$ major pest species do not prefer elicitor-treated plants over untreated plants [45].

- $\quad$ reduced environmental hazards as elicitors affect directly the crop plant and their acute toxicity to other organisms is lower than that of pesticides.

- $\quad$ as protective agrochemicals, elicitors can be applied with the current spraying technology.

- $\quad$ elicitor treatments could be an alternative to genetically modified (GM) plants [47] for better attraction of natural enemies of pest organisms on cultivated plants.

- $\quad$ elicitor-treated plants bear lower ecological risks and have less resistance from the public than GM technology [48].
The following disadvantages of elicitor treatments can be summarized:

- $\quad$ decreased photosynthesis [8].

- $\quad$ reduced plant growth [8].

- $\quad$ reduced crop plant fitness [38].

- $\quad$ possible reduced quality of timber wood due to an excess of oleoresin production [8].

- $\quad$ pest insect could prefer smell of elicitor compounds compared to clean air [45] which affect orientation behaviour of pest and increase pest pressure.

- $\quad$ some of the elicitor compounds are very expensive products and their use is not cost effective at the moment.

\section{CONCLUSIONS}

There is increasing evidence that elicitors could be used in the future as alternatives to traditional pesticides for managing pathogens and pests in agriculture and nursery production of forest trees. Elicitor treatments will change the chemical composition of the treated plant material. Therefore, with agricultural crops there are risks of altered food quality by increased level of some secondary metabolites e.g [11], which may affect human health. A reduction in flowering and fruit production could also be a problem in annual agricultural crops [38]. In nursery production of forest tree seedlings alterations in seedling chemistry does not affect their commercial quality, but any harmful effect on the seedling growth [8] could be deleterious. Tree seedlings that are too small and slow growing will not survive in competition with other vegetation. In coniferous trees systemic-induced resistance (SIR) represents a common and important phenomenon [49] [50], allowing localised induction by pathogen, herbivore or elicitor to activate defences also in other parts of the plant. However, it forces trees to balance between allocation of resources to growth and defence in growing seedlings. Therefore, dose and timing of elicitor treatments are important in order to obtain seedlings which will be competitive in size when planted in forestation site.

Huber et al. [26] discussed the potential practical applications of MeJA treatment of conifer roots as a pest management strategy. They suggested that MeJA could possibly be added to the irrigation water in forest nurseries to improve conifer seedling protection against pests and pathogens. Efficiency of irrigation treatments and seedling growth performance in nurseries possibly could be improved with inoculations of rhizobacteria, which are known to activate SA pathway and increase pathogen resistance in a host plant [51]. Application with lanolin paste [22], fumigation [32] and spraying [8] treatments with MeJA have also been successful to increase pathogen and pest resistance of small conifer seedlings (Fig. 4). Slow-release paraffin wax pellets have been used to release MeSA in wheat fields [52]. The potted seedlings treated at nurseries may also have better protection against various biotic stresses in their planting sites, particularly if the elicitor is still active in the pot soil surface or in paste applied on bark surface. Coronalon and other synthetic compounds mimicing current elicitors will probably be cheaper to produce than synthetic versions of original elicitor 


Examples of the potential delivery
strategies of elicitors into conifer
seedlings in nurseries

Examples of the potential delivery seedlings in nurseries

\section{The elicitor impacts on direct and indirect pest defence and direct pathogen defence in conifer seedlings}

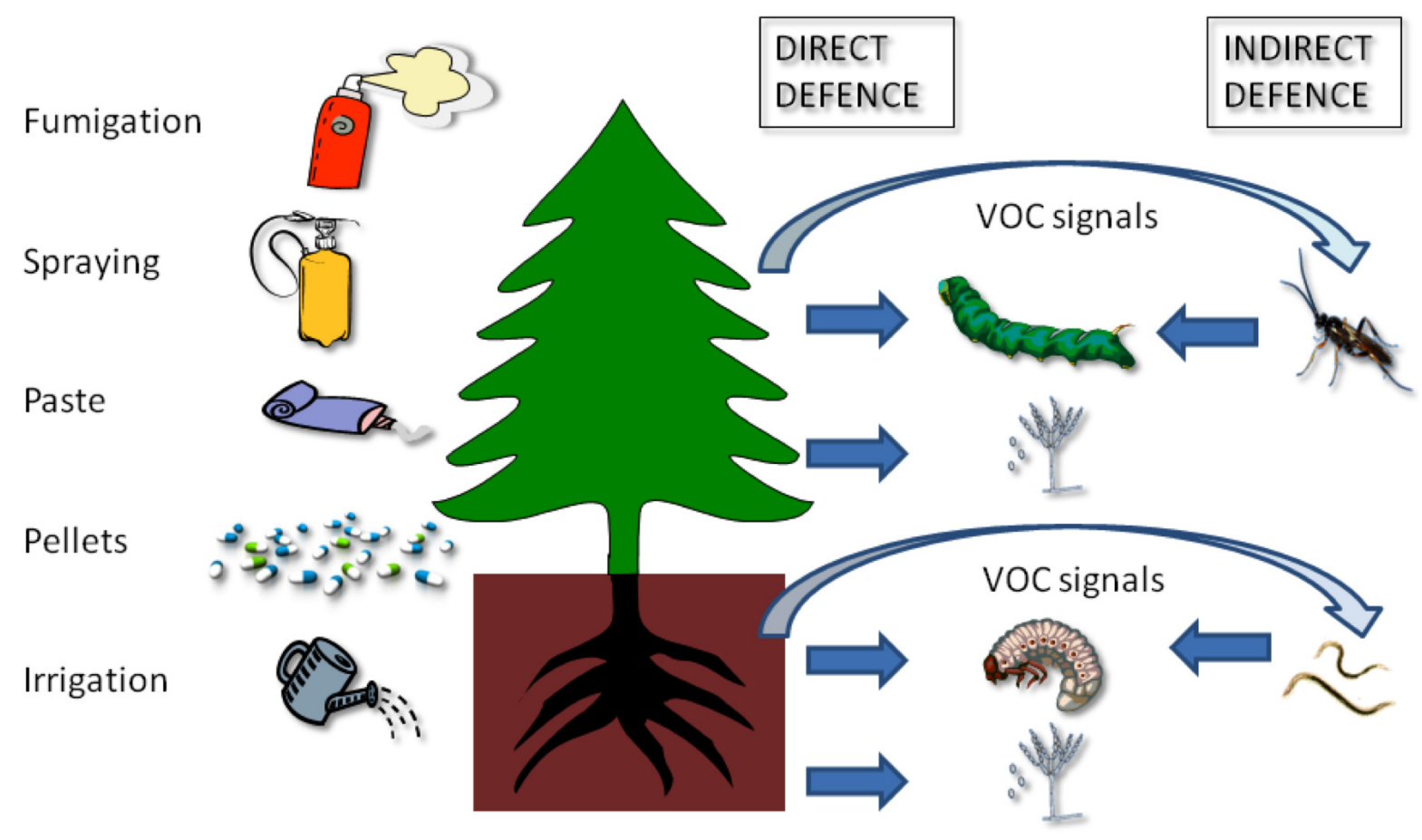

Fig. (4). Summary of the potential delivery strategies of MeJA elicitor in the nursery environments and summary of impacts of elicitor treatments on conifer seedling defence. Systemic defence is affecting directly above-ground and below-ground herbivores and pathogens. Induced plant volatiles (VOCs) will affect indirectly the activity of natural enemies of pests e.g. the parasitoid wasps of moths [45] and the nematode parasitoids of root-feeding beetle larvae [53]. These trophic cascades have potential to reduce feeding damage in seedlings.

compounds and may even have longer lasting effects on seedlings. Therefore, phytohormone mimics might become employed in future cultivation practices for eliciting plant resistance to pests and diseases, but they will require similar extensive safety testing as required for pesticides as they are not natural products. The successful use of commercial BTH in plant pathogen control has already shown that elicitors have a potential to replace more toxic fungicides in future. However, intensive research is needed to develop practical elicitor-based applications in conifer pest and disease management.

\section{ACKNOWLEDGEMENTS}

We thank the Graduate School in Forest Sciences and Academy of Finland (decision no. 202300) for the financial support for our research. Anonymous reviewers and Dr. James Blande gave valuable suggestions for the manuscript.

\section{REFERENCES}

[1] Kauppi PE, Mielikainen K, Kuusela K. Biomass and carbon budget of European forests, 1971 to 1990. Science 1992; 256: 70-4.

[2] Niemelä P, Chapin FS, Danell K, Bryant JP. Herbivory-mediated responses of selected boreal forests to climatic change. Clim Change 2001; 48: 427-40.

[3] Karban R, Baldwin. IT. Induced Responses to Herbivory. Chigaco: The University of Chicago Press; 1997.

[4] Schoonhoven LM, van Loon JJA, Dicke M. Insect-Plant Biology. 2nd ed. Oxford: Oxford University Press; 2005.
[5] Withers ST, Keasling JD. Biosynthesis and engineering of isoprenoid small molecules. Appl Microbiol Biotechnol 2007; 73: 98090 .

[6] Gershenzon J, Croteau R. Terpenoids. In: Rosenthal GA, Berenbaum MR, Eds. Herbivores: Their Interaction with secondary metabolites. Vol. 1. 2nd edition, New York, Academic Press, 1991; 165-219.

[7] Phillips MA, Croteau RB, Resin-based defenses in conifers. Trends Plant Sci 1999; 4: 184-90.

[8] Heijari J, Nerg A-M, Kainulainen P, Viiri H, Vuorinen M Holopainen JK. Application of methyl jasmonate reduces growth, but increases chemical defence and resistance against Hylobius abietis in Scots pine seedlings. Entomol Exp Appl 2005; 115: 117-24.

[9] Roberts SC. Production and engineering of terpenoids in plant cell culture. Nat Chem Biol 2007; 3: 387-95.

[10] Vuorinen T, Nerg AM, Syrjälä L, Peltonen P, Holopainen JK. Epirrita autumnata induced VOC emission of Silver birch differ from emission induced by leaf fungal pathogen. Arthropod-Plant Interactions 2007; 1: 159-65.

[11] Loivamäki M, Holopainen JK, Nerg AM. Chemical changes induced by methyl jasmonate in oilseed rape grown in the laboratory and in the field. J Agric Food Chem 2004; 52: 7607-13.

[12] Bartram S, Jux A, Gleixner G, Boland W. Dynamic pathway allocation in early terpenoid biosynthesis of stress-induced lima bean leaves. Phytochemistry 2006; 67: 1661-72.

[13] Hagerman AE, Butler LG. Tannins and lignins. In: Rosenthal GA, Berenbaum MR, Eds. Herbivores: Their Interaction with secondary metabolites. Vol. 1. 2nd edition, New York, Academic Press, 1991; 79-121.

[14] Hartmann, T. Alkaloids. In: Rosenthal GA, Berenbaum MR, Eds. Herbivores: Their Interaction with secondary metabolites. Vol. 1 2nd edition, New York, Academic Press, 1991; 355-88. 
[15] Keinänen M, Oldham NJ, Baldwin IT. Rapid HPLC screening of jasmonate-induced increases in tobacco alkaloids, phenolics, and diterpene glycosides in Nicotiana attenuata. J Agric. Food Chem 2001; 49: 3553-8.

[16] Engelberth J, Koch T, Schuler G, Bachmann N, Rechtenbach J, Boland W. Ion channel-forming alamethicin is a potent elicitor of volatile biosynthesis and tendril coiling. Cross talk between jasmonate and salicylate signaling in lima bean. Plant Physiol 2001; 125: 369-77.

[17] Belhadj A, Telef N, Cluzet S, Bouscaut J, Corio-Costet MF, Merillon JM. Ethephon elicits protection against Erysiphe necator in grapevine. J Agric Food Chem 2008; 56: 5781-7.

[18] Schuler G, Mithofer A, Baldwin IT, et al. Coronalon: a powerful tool in plant stress physiology. Febs Lett 2004; 563: 17-22.

[19] EPA Pesticides: registration of Methyl salicylate. http://www.epa. gov/oppsrrd1/reregistration/REDs/methyl salicylate red.pdf 2005 [Access date: February 4, 2009].

[20] Hukkanen A, Kostamo K, Kärenlampi S, Kokko H. Impact of agrochemicals on Peronospora sparsa and phenolic profiles in three Rubus arcticus cultivars. J Agric Food Chem 2008; 56: 100816.

[21] Bautista-Banos S, Hernandez-Lauzardo AN, Velazquez-del Valle $\mathrm{MG}$, et al. Chitosan as a potential natural compound to control pre and postharvest diseases of horticultural commodities. Crop Prot 2006; 25: 108-18

[22] Franceschi VR, Krekling T, Christiansen E. Application of methyl jasmonate on Picea abies (Pinaceae) stems induces defence-related responses in phloem and xylem. Am J Bot 2002; 89: 578-86.

[23] Martin D, Tholl D, Gershenzon J, Bohlmann J. Methyl jasmonate induces traumatic resin ducts, terpenoid resin biosynthesis, and terpenoid accumulation in developing xylem of Norway spruce stems. Plant Physiol 2002; 129: 1003-18.

[24] Hudgins JW, Christiansen E, Franceschi VR. Methyl jasmonate induces changes mimicking anatomical defenses in diverse members of the Pinaceae. Tree Physiol 2003; 23: 361-71.

[25] Heijari J, Nerg A-M, Kainulainen P, Vuorinen M, Holopainen JK. Long-term effects of exogenous methyl jasmonate application on Scots pine (Pinus sylvestris L.) needle chemical defence and diprionid sawfly performance. Entomol Exp Appl 2008; 128: 162-71.

[26] Huber DPW, Philippe RN, Madilao LL, Sturrock RN, Bohlmann J. Changes in anatomy and terpene chemistry in roots of Douglas-fir seedlings following treatment with methyl jasmonate. Tree Physiol 2005; 25: 1075-83.

[27] Alfaro RI. An induced defense reaction in white spruce to attack by the white pine weevil, Pissodes strobi. Can J For Res 1995; 25: 1725-30.

[28] Phillips MA, Walter MH, Ralph SG, et al. Functional identification and differential expression of 1-deoxy-D-xylulose 5-phosphate synthase in induced terpenoid resin formation of Norway spruce (Picea abies). Plant Mol Biol 2007; 65: 243-57.

[29] Lapointe G, Luckevich MD, Seguin A. Investigation on the induction of 14-3-3 in white spruce. Plant Cell Rep 2001; 20: 79-84.

[30] Miller B, Madilao LL, Ralph S, Bohlmann J. Insect-induced conifer defense. White pine weevil and methyl jasmonate induce traumatic resinosis, de novo formed volatile emissions, and accumulation of terpenoid synthase and putative octadecanoid pathway transcripts in Sitka spruce. Plant Physiol 2005; 137: 369-82.

[31] Krokene P, Nagy NE, Solheim, H. Methyl jasmonate and oxalic acid treatment of Norway spruce: anatomically based defense responses and increased resistance against fungal infection. Tree Physiol 2008; 28: 29-35.

[32] Kozlowski G, Buchala A, Métraux JP. Methyl jasmonate protects Norway spruce [Picea abies (L.) Karst.] seedlings against Pythium ultimum Trow. Physiol Molec Plant Pathol 1999; 55: 53-8.

[33] Ali Z, Smith I, Guest DI. Combinations of potassium phosphonate and Bion (acibenzolar-S-methyl) reduce root infection and dieback of Pinus radiata, Banksia integrifolia and Isopogon cuneatus caused by Phytophthora cinnamomi. Australasian Plant Pathol 2000; 29: 59-63.

[34] Gref R, Ericsson A. Wound-induced changes of resin acid concentrations in living bark of Scots pine seedlings. Can J For Res 1984; 15: $92-6$

[35] Omer AD, Thaler JS, Granett J, Karban R. Jasmonic acid induced resistance in grapevines to a root and leaf feeder. J Econ Entomol 2000; 93: 840-5.

[36] Thaler JS, Fidantsef AL, Duffey SS, Bostock RM. Trade-offs in plant defense against pathogens and herbivores: A field demonstration of chemical elicitors of induced resistance. J Chem Ecol 1999; 25: $1597-609$.

[37] Thaler JS, Karban R, Ullman DE, Boege K, Bostock RM. Crosstalk between jasmonate and salicylate plant defense pathways: effects on several plant parasites. Oecologia 2002; 131: 227-35

[38] Boughton AJ, Hoover K, Felton GW. Impact of chemical elicitor applications on greenhouse tomato plants and population growth of the green peach aphid, Myzus persicae. Entomol Exp Appl 2006; 120: $175-88$

[39] Kessler A, Baldwin IT. Defensive function of herbivore-induced plant volatile emissions in nature. Science 2001; 291: 2141-4.

[40] Dicke M, Agrawal AA, Bruin J. Plants talk, but are they deaf? Trends Plant Sci 2003; 8: 403-5.

[41] Holopainen JK. Multiple functions of inducible plant volatiles. Trends in Plant Sci 2004; 9: 529-33.

[42] Thaler JS. Jasmonate-inducible plant defenses cause increased parasitism of herbivores. Nature 1999; 399: 686-8.

[43] Martin DM, Gershenzon J, Bohlmann J. Induction of volatile terpene biosynthesis and diurnal emission by methyl jasmonate in foliage of Norway Spruce. Plant Physiol 2003; 132: 1586-99.

[44] Kännaste A, Vongvanich N, Borg-Karlson AK. Infestation by a Nalepella species induces emissions of $\alpha$ - and $\beta$-farnesenes, (-)linalool and aromatic compounds in Norway spruce clones of different susceptibility to the large pine weevil. Arthropod-Plant Interact 2008; $2: 31-41$.

[45] Ibrahim MA, Nissinen A, Holopainen JK. The response of Plutella xylostella and its parasitoid Cotesia plutellae to volatile compounds. J Chem Ecol 2005; 31: 1969-84.

[46] James DG, Grasswitz TR. Synthetic herbivore-induced plant volatiles increase field captures of parasitic wasps. Biocontrol 2005; 50 : 871-80.

[47] Kappers IF, Aharoni A, van Herpen T, Luckerhoff LLP, Dicke M, Bouwmeester HJ. Genetic engineering of terpenoid metabolism attracts, bodyguards to Arabidopsis. Science 2005; 309: 2070-2

[48] Poppy GM, \& M.J. Wilkinson Gene Flow from GM plants - A manual for assessing, measuring and managing the risks. Oxford. Blackwell Publishing 2005.

[49] Bonello P, Gordon TR, Herms DA, Wood DL, Erbilgin N. Nature and ecological implications of pathogen-induced systemic resistance in conifers: A novel hypothesis. Physiol Molec Plant Pathol 2006; 68: 95-104.

[50] Blande JD, Turunen K, Holopainen JK. Pine weevil feeding on Norway spruce bark has a stronger impact on needle VOC emissions than enhanced UV-B radiation. Environ Pollut 2009; 157: 174-80.

[51] Barriuso J, Solano BR, Manero FJG. Protection against pathogen and salt stress by four plant growth-promoting rhizobacteria isolated from Pinus sp on Arabidopsis thaliana. Phytopathology 2008; 98: 666-72.

[52] Prinsloo G, Ninkovic V, van der Linde TC, van der Westhuizen AJ, Pettersson J, Glinwood R. Test of semiochemicals and a resistan wheat variety for russian wheat aphid management in South Africa. J Appl Entomol 2007; 131: 637-44.

[53] Rasmann S, Kollner TG, Degenhardt J, et al. Recruitment of entomopathogenic nematodes by insect-damaged maize roots. Nature 2005; 434: 732-7. 